\title{
Transitions between food insecurity and food security predict children's social skill development during elementary school
}

\author{
Larry L. Howard* \\ Department of Economics, California State University, Fullerton, 800 North State College Boulelvard, Fullerton, \\ CA 92834-6848, USA
}

(Received 31 March 2010 - Revised 25 November 2010 - Accepted 30 November 2010 - First published online 27 January 2011)

\begin{abstract}
Recent findings indicate that household food insecurity affects children's social skill development in the early years of elementary school. It is important to assess the persistency of developmental consequences and investigate whether all categories of social skills are equally affected by food insecurity experiences. The present paper estimates population-averaged and subject-specific models for children's social skill scores reported by school teachers using longitudinal data on 2310 boys and 2400 girls in the USA enrolled in the 1st (aged 6-9 years), 3rd (aged 8-11 years) and 5th (aged 10-13 years) grades (1999-2003) from the Early Childhood Longitudinal Study-Kindergarten. The main findings are, first, significantly $(P<0.05)$ negative, contemporaneous and transitional relationships between food insecurity experiences and children's social skill scores are evident. Estimates based on sex-stratified samples indicate that the contemporaneous association is strongest among girls, while the association of an early transition from food insecurity in the 1st grade to food security in the 3rd grade is strongest among boys. Second, food insecurity experiences predict children's social skill scores emphasising self-control, attentiveness and task persistence, rather than interpersonal relationships or externalising behaviour. Overall, the findings underscore the multifaceted effect that household food insecurity has on children's social skills and provide the strongest empirical evidence to date that the experiences are linked with non-nutritional developmental consequences for children over a time horizon spanning several years.
\end{abstract}

Key words: Food insecurity: Child development: Social skills: Longitudinal data

Although widespread hunger and malnutrition are uncommon in the established market economies of Europe and North America, an increasing number of households often forgo or limit dietary intake because of financial hardship. The prevalence of food insecurity in the USA has now reached its highest level since regular monitoring began in 1995, and over eight million households with children (21\% of the total) reported an inability to afford nutritionally adequate food in $2008^{(1)}$. While the intensity of food insecurity ranges from temporary interruptions in usual diet to chronic hunger, the experiences in developed countries can frequently involve a concurrent combination of over- and undernourishment ${ }^{(2)}$. The research investigating dietary behaviour has linked increasing financial constraints ${ }^{(3,4)}$ and prevailing inverse relationships between energy cost $(€ / \mathrm{MJ})$ and energy density $(\mathrm{kJ} / \mathrm{g})$ of available foods ${ }^{(5-8)}$ to an imbalance of macro- and micronutrient intakes. Moreover, food insecurity is negatively associated with food spending among households in the $\mathrm{USA}^{(1)}$, and the substitution of low-cost, energy-dense meals for healthy meals can exacerbate the intensity of food insecurity within a household if children gain weight ${ }^{(9,10)}$.

Food insecurity experiences encompass a wide range of deleterious effects associated with hunger ${ }^{(11,12)}$ and are negatively associated with physical and mental health and learning outcomes for children ${ }^{(13-22)}$. However, the evidence on relationships between food insecurity and social skill development is less clear. Among children aged 6-12 years, the experience is positively associated with measures of aggression, anxiety and hyperactivity ${ }^{(11,13)}$, yet not significantly related to other measures of aggression, attentiveness and shyness ${ }^{(13,14)}$. Only one earlier study has used longitudinal methods to examine relationships between food insecurity and children's social skill development ${ }^{(21)}$. While the experiences were not significantly related to composite measures of social skills overall, sex-stratified analysis revealed a positive association for boys and a negative association for girls. A limitation of the earlier study was the use of composite outcome measures that comprise several categories of social skills, and broad conclusions drawn from composite analyses may be incomplete if the effects are not equal for each component skill category. Although statistical measures of reliability, such as the Cronbach $\alpha^{(23)}$, indicate the degree to which individual outcomes are inter-related, it is not certain that children's social skill development is a one-dimensional outcome with regard to food insecurity. 
Given the multifaceted threat of food insecurity, recent models of children's social skill development have emphasised the possibility of both contemporaneous and transitional relationships with the experiences ${ }^{(21)}$. Theoretical motivation for distinguishing between the two effects is grounded in the nutritional and psychological components of the household food insecurity measures in developed countries ${ }^{(24-26)}$. Food insecurity is linked with decreases in the energy sufficiency and nutrient adequacy of children's diets ${ }^{(22)}$, and temporary adjustments can negatively affect children's observed social skills. For instance, metabolic stress is linked with impairment of attention and memory processes among children aged 9-11 years ${ }^{(27)}$ and the voluntary exertion of effort during school among children aged 10 years ${ }^{(28)}$. However, food insecurity experiences can also negatively affect children's social adjustment in ways that persist, even if the financial circumstances of households improve. For instance, financial hardship is negatively associated with children's self-esteem $^{(29)}$, and recent past exposure to environmental adversity is positively associated with children's problem behaviours reported by school teachers ${ }^{(30)}$. A comprehensive, longitudinal modelling approach taking into account the potential for contemporaneous and transitional relationships is necessary to gain further insight into how food insecurity experiences affect children's social skills during elementary school.

\section{Experimental methods}

\section{Study sample}

The Early Childhood Longitudinal Study-Kindergarten began in the autumn of 1998 by observing nearly 20000 children in kindergarten enrolled in over 1200 schools throughout the USA. The present study was conducted according to the guidelines laid down in the Declaration of Helsinki, and all procedures involving human subjects/patients were approved by the ethics committees of the Department of Education and Office of Management and Budget, USA. Written informed consent was obtained from all subjects/ patients. Attrition due to geographical relocation resulted in approximately 11000 children remaining in the study from kindergarten to 5 th grade, and the locatable students were followed for a random $50 \%$ of the schools ${ }^{(31)}$. Our analytic sample consists of 4710 children for whom full data were available for the $1 \mathrm{st}, 3 \mathrm{rd}$ and 5 th grades, respectively. Demographic characteristics of our analytic sample were similar to the full sample, and the available longitudinal sampling weights are utilised in the analysis to adjust for an oversampling of Asian and Pacific Islanders and non-response across the three survey rounds.

\section{Social skill outcome measures}

Questionnaires were administered to children's teachers in the spring of the 1st, $3 \mathrm{rd}$ and 5 th grades that asked them to report how often students exhibited certain social skills in class. The response scales and measures were adapted from an existing social skill rating system ${ }^{(32)}$, and the reliability for the teacher-reported social skill observations was high ${ }^{(31)}$. The responses ranged from 1 (never) to 4 (very often), and we focus on the four most reliable social skill scores: interpersonal relationships, self-control; approaches to learning; externalising behaviour. For comparison with earlier studies, we construct composite social skill scores by taking the average of the four component scores with the scorings for externalising behaviour reversed. The Cronbach $\alpha^{(23)}$ for children's composite scores was high at 0.883, 0.895 and 0.900 for the 1 st, 3 rd and 5 th grades, respectively.

Of the four social skill outcomes, interpersonal relationships' measures a child's ability in forming and maintaining friendships, getting along with people who are different, comforting or helping other children, expressing feelings, ideas and opinions in positive ways, and showing sensitivity to the feelings of others. 'Self-control' measures a child's ability in respecting the property rights of others, controlling temper, accepting peer ideas for group activities and responding appropriately to pressure from peers. 'Approaches to learning' measures a child's ability to exhibit skills such as attentiveness, task persistence, eagerness to learn, learning independence, flexibility and organisation. 'Externalising behaviour' measures a child's ability to behave in ways that interfere with the learning process in the classroom such as arguing, fighting, getting angry, acting impulsively and disturbing ongoing activities; higher values indicate a worse developmental outcome.

\section{Food insecurity measures}

Food insecurity levels in children's home environments in the previous 12 months were assessed using the United States Department of Agriculture's Household Food Security Survey Module. It consists of eighteen questions that are designed to capture information about the household environment such as anxiety over insufficient food budget or supply, perceptions of inadequate food quality or quantity, and instances of reduced food intake by household members; and each question specifies that the circumstance must have occurred in the past 12 months due to financial limitations $^{(25)}$. For comparison with earlier studies, we measure contemporaneous food insecurity using an indicator variable for households reporting $(\geq 1$ ) affirmative responses on the module.

To capture transitional effects associated with the timing of food insecurity experiences, we construct indicator variables for each of the eight possible patterns. For observations in the 3rd grade, we classify households according to whether they became food secure or food insecure for the first time. For observations in the 5th grade, we classify households according to whether they became food secure or food insecure for the first time or for the second time. We classify households that do not experience a change in food security or food insecurity status from the 1 st to the 5 th grade as persistently food secure and persistently food insecure, respectively. 


\section{Control measures}

Extensive data were collected in the spring of each grade using one-on-one, untimed direct child assessments and parent interviews conducted by telephone ${ }^{(31)}$. Time-invariant control variables used in the analysis are age, sex, developmental disability status and race-ethnicity. The time-varying control variables measure child-specific and ecological factors influencing social skill development. Children's heights and body weights were measured in each round using a Shorr Board (Shorr Production, Olney, MD, USA) and digital scale, respectively; duplicate measures were taken and we use the mean values. Parents reported on the overall activity level of their children relative to other children of the same age, and we constructed three categorical variables: low, high and very high overall activity level, with normal overall activity level as the reference group. Additional time-varying control variables include the average number of minutes per day a child watches television, the number of hours/ week a child spends in non-parental child care, a variable indicating whether the child cares for self when not in school, a variable indicating whether the child is placed in centre-based care when not in school and a variable indicating whether the child attends a public school. At the household level, time-varying controls include the number of siblings, the overall household size, a series of indicator variables corresponding to household income categories in US $\$ 1000(<5,5-10,10-15,15-20,20-25,25-30,30-35$, $35-40,40-50,50-75,75-100,100-200$ and >200) and a series of indicator variables corresponding to parental education levels (8th grade or below, 9th-12th grade, high school diploma/General Equivalency Diploma (GED), vocational programme, some college, bachelor's degree, graduate/professional school with no degree, master's degree, doctorate or professional degree).

Several additional variables control for potential confounding effects of the local economic and non-economic environment on household transitions between food security and food insecurity. First, information on US counties is linked to each child based on the location of the elementary school they attend. A series of county-level indicator variables are constructed to control for any time-invariant characteristics of the local environment that are correlated with the likelihood of children's households experiencing food insecurity. Second, we control for time-varying characteristics of the local county environment during the previous year when food insecurity was assessed by using measures of Food Stamp programme recipients (per capita), the unemployment rate and average household income. Third, general linear time trends by county and by the type of school are utilised to further minimise any remaining possibility of spurious associations among the variables of interest.

\section{Models}

Contemporaneous and transitional relationships between food insecurity experiences and children's social skill scores are investigated using population-averaged and subject-specific regression models. Because the teachers reporting on children's performance and the specific questions in the social skill questionnaires change across survey rounds, a static relationship between repeated observations is assumed in the empirical models, and correlation among repeated child observations is accounted for in the estimation. The first model postulated for the $i$ th child's social skill score at time $t$ is given in equation 1 :

$\begin{aligned} \text { Score }_{i t}= & \left.\beta_{0}+\beta_{1} \text { (contemporaneous food insecurity }\right)_{i t} \\ & +\beta_{2} \text { (became food secure for the first time } \\ & \text { in 3rd grade) } i t \\ & +\beta_{3} \text { (became food insecure for the first time }\end{aligned}$

in 3 rd grade) $)_{i t}$

$+\beta_{4}$ (became food secure for the first time

in 5 th grade) $)_{i t}$

$+\beta_{5}$ (became food insecure for the first time

in 5 th grade) $)_{i t}$

$+\beta_{6}$ (became food secure for the second

time in 5 th grade) $_{i t}$

$+\beta_{7}$ (became food insecure for the second

time in 5 th grade $_{i t}$

$+\beta_{8}$ (persistently food insecure) ${ }_{i}$

$+\beta_{9}$ (time-invariant covariates) $_{i}$

$+\beta_{10}$ (time-varying covariates $)_{i t}+E_{i t}$.

Within-child (subject) correlation is accounted for in the computation of coefficient standard errors under the assumption that $E_{i t}=c_{i}+e_{i t}$, where $c_{i}$ captures the time-invariant subject-specific correlation among repeated outcomes. This particular formulation of the model is appropriate when the aggregate response for the entire population of children is of interest, and hence provides the population-averaged marginal response ${ }^{(33)}$. The estimated $\beta_{1}-\beta_{8}$ coefficients indicate the difference in social skill scores for children from households that are experiencing food insecurity and transitioning between states of food insecurity and food security relative to children from households with persistent food security. Population-averaged models allow us to attribute marginal effects to time-invariant characteristics such as living in a household that is persistently food insecure; however, a practical limitation is that unbiased estimation requires that $c_{i}$ is uncorrelated with the explanatory variables. 
As an alternative, we estimate the following subject-specific regression model given in equation 2 :

Score $_{i t}=\beta_{0}+\beta_{1}$ (contemporaneous food insecurity $)_{i t}$

$+\beta_{2}$ (became food secure for the first time

in 3 rd grade) $)_{i t}$

$+\beta_{3}$ (became food insecure for the first time

in 3 rd grade) $)_{i t}$

$+\beta_{4}$ (became food secure for the first time

in 5 th grade $_{i t}$

$+\beta_{5}$ (became food insecure for the first time

in 5 th grade) $)_{i t}$

$+\beta_{6}$ (became food secure for the second time in 5 th grade) $_{i t}$

$+\beta_{7}$ (became food insecure for the second time in 5 th grade $_{i t}$

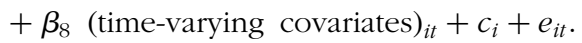

In contrast to the population-averaged model in equation 1 , the subject-specific model in equation 2 explains the source of the covariance among repeated observations for a child by explicitly modelling the time-invariant shared subject effects, $c_{i}$, in the conditional mean ${ }^{(33)}$. This approach provides the least biased estimates of the effects of the explanatory variables by controlling for the influence of all unobservable (and observed) time-invariant factors affecting children's social skill development.

\section{Statistical methods}

Population-averaged and subject-specific linear regression methods are utilised to estimate the contemporaneous and transitional relationships between food insecurity experiences and children's social skill scores. The Stata xtreg (version 11; StataCorp LP; College Station, TX, USA) procedure is used in the estimation, and the cluster procedure is used to allow for an arbitrary pattern of correlation among repeated child observations in subject-specific models. Early Childhood Longitudinal Study-Kindergarten longitudinal sampling weights are utilised in all models to adjust for an oversampling of Asian and Pacific Islanders and non-response. Analyses are conducted using the full sample and sex-stratified samples. Differences are considered significant at the $5 \%$ level $(P<0.05)$.

\section{Results}

\section{Descriptive statistics for transitions between food} insecurity and food security

The sample means of the variables utilised in the models are reported in Table 1. Approximately 9-11\% of children were from households experiencing food insecurity in any one time period, while $81 \%$ were from persistently food secure households and 3\% were from persistently food insecure households. Of the $11 \%$ of children experiencing food insecurity in the 1 st grade, $7 \%$ transitioned to food security for the first time in the 3 rd grade. Of the $9 \%$ of children experiencing food insecurity in the 3 rd grade, $1 \%$ transitioned to food security for the first time in the 5 th grade and $3 \%$ transitioned to food security for the second time in the 5 th grade. In contrast, $5 \%$ of children transitioned to food insecurity for the first time in the $3 \mathrm{rd}$ grade, $4 \%$ of children transitioned to food insecurity for the first time in the 5 th grade and $2 \%$ of children transitioned to food insecurity for the second time in the 5 th grade.

\section{Results for children's social skill development}

Table 2 presents the results from the population-averaged model in equation 1 for each of the four social skill score outcomes and a composite. Contemporaneous food insecurity and persistent food insecurity are not significantly related to changes in children's social skill scores. Relative to children from households that are persistently food secure, children who experience a transition from food insecurity in the 1st grade to food security in the 3 rd grade have significantly lower composite social skill scores $\left(\beta_{2}=-0 \cdot 113, P<0 \cdot 019\right)$. Stratification by sex shows that the association between this early transition and composite social skill scores is significant for boys $\left(\beta_{2}=-0 \cdot 188, P<0 \cdot 005\right)$ and close in magnitude to zero for girls $\left(\beta_{2}=-0.036, P<0.566\right)$. A similar pattern by sex is evident for each of the component social skill scores measuring interpersonal relationships, self-control, approaches to learning and externalising behaviour.

To assess the potential bias in the estimates of the population-averaged model, Table 3 presents the results from the subject-specific model in equation 2 for each of the four social skill score outcomes and a composite. Children's composite social skill scores are negatively associated with contemporaneous food insecurity experiences $\left(\beta_{1}=-0.077\right.$, $P<0.036)$ and an early transition from food insecurity in the 1 st grade to food security in the 3rd grade $\left(\beta_{2}=-0 \cdot 132\right.$, $P<0.008)$. Thus, children with intermittent food insecurity beginning in the 1 st grade have composite social scores that are nearly 0.50 standard deviations lower overall, and 0.25 standard deviations lower relative to children with intermittent food insecurity in later grades, on average.

Stratification by sex further reveals significant differences in the relationship between food insecurity and social skills; the contemporaneous association is strongest for girls $\left(\beta_{1}=-0.119, P<0.016\right)$, while the association of an early transition from food insecurity in the 1 st grade to food security in the 3 rd grade is strongest for boys $\left(\beta_{2}=-0 \cdot 172, P<0 \cdot 012\right)$. Furthermore, in contrast to results from the populationaveraged model, the early transition is not a significant predictor of boys' social skill scores for interpersonal relationships $\left(\beta_{2}=-0 \cdot 167, P<0.066\right)$ and externalising behaviour $\left(\beta_{2}=0 \cdot 180, P<0 \cdot 070\right)$, and contemporaneous food insecurity is a significant predictor of girls' social skill scores for selfcontrol $\left(\beta_{1}=-0 \cdot 124, P<0 \cdot 050\right)$ and approaches to learning 
Table 1. Selected variables for children in the Early Childhood Longitudinal Study-Kindergarten observed at 2-year intervals in the period 1999-2003* (Mean values and standard deviations for 4710 subjects)

\begin{tabular}{|c|c|c|c|c|c|c|}
\hline \multirow[b]{2}{*}{ Variables } & \multicolumn{2}{|c|}{ 1st grade } & \multicolumn{2}{|c|}{ 3rd grade } & \multicolumn{2}{|c|}{ 5th grade } \\
\hline & Mean & SD & Mean & SD & Mean & SD \\
\hline Social skill composite score $(n)$ & 2.01 & 0.52 & 1.99 & 0.52 & 1.99 & 0.52 \\
\hline Interpersonal relationship score $(1-4)$ & 3.19 & 0.61 & $3 \cdot 17$ & 0.62 & $3 \cdot 14$ & 0.62 \\
\hline Self-control score $(1-4)$ & 3.26 & 0.57 & 3.26 & 0.58 & $3 \cdot 28$ & 0.58 \\
\hline Approaches to learning score $(1-4)$ & 3.18 & 0.64 & $3 \cdot 16$ & 0.64 & $3 \cdot 16$ & 0.65 \\
\hline Externalising problem behaviour score $(1-4)$ & 1.57 & 0.58 & 1.63 & 0.56 & 1.60 & 0.54 \\
\hline Contemporaneous food insecurity (\%) & 11 & & 9 & & 11 & \\
\hline Persistently food secure (\%) & 81 & & - & & - & \\
\hline Persistently food insecure (\%) & 3 & & - & & - & \\
\hline Became food secure for the first time in 3rd grade (\%) & - & & 7 & & - & \\
\hline Became food insecure for the first time in 3rd grade (\%) & - & & 5 & & - & \\
\hline Became food secure for the first time in 5 th grade $(\%)$ & - & & - & & 1 & \\
\hline Became food insecure for the first time in 5 th grade (\%) & _- & & _ & & 4 & \\
\hline Became food secure for the second time in 5 th grade $(\%)$ & - & & - & & 3 & \\
\hline Became food insecure for the second time in 5th grade (\%) & - & & - & & 2 & \\
\hline Black household (\%) & 7 & & - & & - & \\
\hline Hispanic (of all races) household (\%) & 12 & & - & & - & \\
\hline Siblings $(n)$ & 1.46 & 1.04 & 1.49 & 1.05 & 1.48 & 1.04 \\
\hline Household size $(n)$ & 4.50 & 1.22 & 4.49 & $1 \cdot 22$ & 4.47 & 1.23 \\
\hline Parental education level (1-9) & $5 \cdot 26$ & 1.84 & 5.42 & 1.83 & 5.48 & 1.83 \\
\hline Household income category $(1-13)$ & 8.88 & 2.80 & $9 \cdot 14$ & $2 \cdot 72$ & $9 \cdot 26$ & 2.76 \\
\hline Age (months) & $87 \cdot 19$ & 4.28 & - & & - & \\
\hline Boys $(\%)$ & 49 & & - & & - & \\
\hline Developmental disability (\%) & 14 & & - & & - & \\
\hline Height $(\mathrm{m})$ & 1.23 & 0.06 & 1.35 & 0.07 & 1.47 & 0.08 \\
\hline Weight (kg) & 25.79 & $5 \cdot 71$ & 34.11 & 8.92 & 44.08 & 12.42 \\
\hline Low overall activity level (\%) & 3 & & 6 & & 8 & \\
\hline High overall activity level (\%) & 31 & & 29 & & 28 & \\
\hline Very high overall activity level (\%) & 14 & & 15 & & 16 & \\
\hline Television watching $(\mathrm{min} / \mathrm{d})$ & $112 \cdot 57$ & 67.26 & $114 \cdot 11$ & 68.83 & $121 \cdot 21$ & $71 \cdot 24$ \\
\hline Non-parental care (h/week) & 4.80 & 7.95 & 3.68 & 6.73 & 3.18 & 6.65 \\
\hline Cares for self when not in school (\%) & 2 & & 4 & & 13 & \\
\hline Centre-based care when not in school (\%) & 15 & & 13 & & 10 & \\
\hline Parental care when not in school (\%) & 55 & & 60 & & 57 & \\
\hline Attends public school (\%) & 74 & & 75 & & 75 & \\
\hline County-level characteristics $\dagger$ & & & & & & \\
\hline Unemployment rate (\%) & 4 & 2 & 5 & 2 & 6 & 2 \\
\hline Food stamp recipients (per capita) & 6 & 5 & 6 & 5 & 8 & 5 \\
\hline Income ( $\$$ per capita) & $28404 \cdot 28$ & $8110 \cdot 78$ & $30407 \cdot 75$ & $8850 \cdot 84$ & $31515 \cdot 11$ & 8480.99 \\
\hline
\end{tabular}

${ }^{*}$ Food insecurity is defined as $\geq 1$ affirmative response on the United States Department of Agriculture's Household Food Security Survey Module.

† County-level unemployment rate data are from the US Bureau of Labor Statistics. Food stamp recipient data are from the County Level Food Stamp Recipient File, US Bureau of the Census. County-level per capita income data are from the Regional Economic Information System, US Department of Commerce, Bureau of Economic Analysis, Regional Economic Measurement Division.

( $\left.\beta_{1}=-0 \cdot 190, P<0 \cdot 003\right)$. Overall, the change in magnitude and precision of the estimated effects between the two models indicates that unobservable time-invariant characteristics of children and their households are correlated with both food insecurity experiences and observed social skills in elementary school

\section{Discussion}

The comprehensive, longitudinal modelling approach of the study emphasised the multifaceted threat of household food insecurity to children's social skill development through both contemporaneous and transitional relationships. Several insights into how food insecurity experiences affect the social skills of children aged 6-13 years in the USA are evident from the empirical results. In particular, we find that children have below-average social skill scores during the same time period in which their households report food insecurity.
A negative contemporaneous effect of food insecurity experiences on children's social skills is consistent with a concurrent combination of unhealthy changes in dietary intake and psychological stress; and estimates based on sex-stratified samples indicate that the association is strongest among girls. Previous analyses of $24 \mathrm{~h}$ recall data indicate that food insecurity is linked with a reduced consumption of fruit and vegetables and a higher prevalence of nutrient inadequacy for protein among girls aged 9-13 years in Canada ${ }^{(22)}$; however, a comparable sex-stratified analysis does not exist for the USA. To the extent that food insecurity acts as a psychological stressor, earlier studies have shown that girls are more likely to experience emotional distress such as anxiety and depression in response to household financial hardship and stress ${ }^{(34,35)}$. Moreover, parental depression resulting from financial hardship is negatively associated with adolescent girls' social adjustment ${ }^{(36)}$. 
Table 2. Estimates from population-averaged models of the contemporaneous and transitional effects of household food insecurity experiences on children's social skill scores in elementary school*†

( $\beta$-Coefficients and $P$ values)

\begin{tabular}{|c|c|c|c|c|c|c|c|c|c|c|c|c|c|c|c|c|c|}
\hline \multirow[b]{2}{*}{ Outcome } & \multirow[b]{2}{*}{$n$} & \multicolumn{2}{|c|}{$\begin{array}{l}\text { Contemporaneous } \\
\text { food insecurity }\end{array}$} & \multicolumn{2}{|c|}{$\begin{array}{l}\text { Became food } \\
\text { secure for the } \\
\text { first time in } \\
\text { 3rd grade }\end{array}$} & \multicolumn{2}{|c|}{$\begin{array}{l}\text { Became food } \\
\text { insecure for the } \\
\text { first time in } \\
\text { 3rd grade }\end{array}$} & \multicolumn{2}{|c|}{$\begin{array}{l}\text { Became food } \\
\text { secure for the } \\
\text { first time in } \\
5 \text { th grade }\end{array}$} & \multicolumn{2}{|c|}{$\begin{array}{l}\text { Became food } \\
\text { insecure for the } \\
\text { first time in } \\
5 \text { th grade }\end{array}$} & \multicolumn{2}{|c|}{$\begin{array}{l}\text { Became food } \\
\text { secure for the } \\
\text { second time in } \\
\text { 5th grade }\end{array}$} & \multicolumn{2}{|c|}{$\begin{array}{l}\text { Became food } \\
\text { insecure for the } \\
\text { second time in } \\
\text { 5th grade }\end{array}$} & \multicolumn{2}{|c|}{$\begin{array}{l}\text { Persistently } \\
\text { food insecure }\end{array}$} \\
\hline & & $\beta$ & $P$ & $\beta$ & $P$ & $\beta$ & $P$ & $\beta$ & $P$ & $\beta$ & $P$ & $\beta$ & $P$ & $\beta$ & $P$ & $\beta$ & $P$ \\
\hline \multicolumn{18}{|c|}{ Social skill composite score } \\
\hline All & 4710 & -0.055 & 0.074 & -0.113 & 0.019 & 0.003 & 0.948 & -0.038 & 0.668 & 0.054 & 0.366 & 0.021 & 0.809 & $0 \cdot 117$ & 0.100 & -0.016 & 0.776 \\
\hline Boys & 2310 & -0.051 & 0.190 & -0.188 & 0.005 & -0.003 & 0.962 & 0.048 & 0.686 & 0.065 & 0.351 & 0.058 & 0.489 & 0.118 & 0.280 & -0.125 & 0.106 \\
\hline Girls & 2400 & -0.047 & 0.267 & -0.036 & 0.566 & -0.012 & 0.821 & -0.066 & 0.561 & 0.058 & 0.491 & 0.001 & 0.993 & 0.097 & 0.147 & $0 \cdot 100$ & 0.164 \\
\hline \multicolumn{18}{|c|}{ Interpersonal relationship score } \\
\hline All & 4710 & -0.073 & 0.061 & -0.106 & 0.052 & 0.030 & 0.604 & -0.054 & 0.621 & 0.032 & 0.651 & 0.027 & 0.785 & 0.184 & 0.100 & -0.001 & 0.993 \\
\hline Boys & 2310 & -0.052 & 0.309 & -0.190 & 0.019 & 0.023 & 0.800 & 0.098 & 0.460 & 0.019 & 0.830 & 0.035 & 0.751 & $0 \cdot 150$ & 0.371 & -0.108 & 0.190 \\
\hline Girls & 2400 & -0.072 & 0.188 & -0.014 & 0.837 & 0.002 & 0.975 & -0.116 & 0.443 & 0.037 & 0.701 & 0.018 & 0.890 & 0.230 & 0.074 & 0.118 & 0.151 \\
\hline \multicolumn{18}{|c|}{ Self-control score } \\
\hline All & 4710 & -0.048 & 0.215 & -0.120 & 0.030 & 0.013 & 0.799 & -0.033 & 0.748 & -0.005 & 0.950 & 0.038 & 0.686 & 0.118 & 0.140 & -0.023 & 0.708 \\
\hline Boys & 2310 & -0.045 & 0.361 & -0.217 & 0.002 & 0.054 & 0.427 & 0.068 & 0.636 & -0.004 & 0.967 & 0.111 & 0.201 & 0.137 & 0.185 & -0.159 & 0.056 \\
\hline Girls & 2400 & -0.049 & 0.343 & -0.022 & 0.761 & -0.032 & 0.659 & -0.092 & 0.478 & 0.020 & 0.846 & -0.015 & 0.903 & 0.081 & 0.342 & 0.129 & 0.100 \\
\hline \multicolumn{18}{|c|}{ Approaches to learning score } \\
\hline All & 4710 & -0.046 & 0.194 & -0.125 & 0.068 & -0.005 & 0.923 & 0.049 & 0.617 & 0.056 & 0.406 & 0.053 & 0.537 & 0.134 & 0.074 & -0.017 & 0.803 \\
\hline Boys & 2310 & -0.020 & 0.674 & -0.156 & 0.009 & -0.063 & 0.437 & 0.208 & 0.159 & 0.042 & 0.611 & 0.060 & 0.596 & 0.138 & 0.192 & -0.109 & 0.227 \\
\hline Girls & 2400 & -0.061 & 0.235 & -0.080 & 0.476 & 0.030 & 0.656 & -0.049 & 0.690 & 0.069 & 0.485 & 0.057 & 0.607 & 0.111 & 0.204 & 0.088 & 0.320 \\
\hline \multicolumn{18}{|c|}{ Externalising behaviour score } \\
\hline All & 4710 & 0.039 & 0.265 & 0.096 & 0.076 & 0.032 & 0.440 & 0.083 & 0.246 & -0.105 & 0.087 & 0.040 & 0.632 & -0.012 & 0.880 & 0.029 & 0.648 \\
\hline Boys & 2310 & 0.075 & 0.141 & 0.189 & 0.048 & 0.026 & 0.685 & 0.148 & 0.156 & -0.162 & 0.094 & 0.001 & 0.991 & -0.017 & 0.884 & 0.136 & 0.167 \\
\hline Girls & 2400 & -0.017 & 0.645 & 0.007 & 0.855 & 0.063 & 0.207 & -0.031 & 0.717 & -0.085 & 0.219 & 0.055 & 0.588 & 0.040 & 0.613 & -0.061 & 0.384 \\
\hline
\end{tabular}

*Food insecurity is defined as $\geq 1$ affirmative response on the United States Department of Agriculture's Household Food Security Survey Module.

$\dagger P$ values are adjusted for within-child correlation among repeated observations, and the use of longitudinal Early Childhood Longitudinal Study-Kindergarten sampling weights adjusted for oversampling and non-response across the three survey rounds.

¥Controlling for child’s age, age-squared, sex, race-ethnicity, disability status, overall activity level, In(height), In(weight), television watching, non-parental child care hours and arrangements, type of school, number of siblings, time-varying county-level characteristics, and a series of county-level indicator variables and linear time trends. 
Table 3. Estimates from subject-specific models of the contemporaneous and transitional effects of household food insecurity experiences on children's social skill scores in elementary school ${ }^{\star} † \ddagger$ $(\beta$-Coefficients and $P$ values)

\begin{tabular}{|c|c|c|c|c|c|c|c|c|c|c|c|c|c|c|c|}
\hline \multirow[b]{2}{*}{ Outcome } & \multirow[b]{2}{*}{$n$} & \multicolumn{2}{|c|}{$\begin{array}{l}\text { Contemporaneous } \\
\text { food insecurity }\end{array}$} & \multicolumn{2}{|c|}{$\begin{array}{l}\text { Became food } \\
\text { secure for the } \\
\text { first time in } \\
\text { 3rd grade }\end{array}$} & \multicolumn{2}{|c|}{$\begin{array}{l}\text { Became food } \\
\text { insecure for the } \\
\text { first time in } \\
\text { 3rd grade }\end{array}$} & \multicolumn{2}{|c|}{$\begin{array}{l}\text { Became food } \\
\text { secure for the } \\
\text { first time in } \\
5 \text { th grade }\end{array}$} & \multicolumn{2}{|c|}{$\begin{array}{l}\text { Became food } \\
\text { insecure for the } \\
\text { first time in } \\
5 \text { th grade }\end{array}$} & \multicolumn{2}{|c|}{$\begin{array}{l}\text { Became food } \\
\text { secure for the } \\
\text { second time in } \\
\text { 5th grade }\end{array}$} & \multicolumn{2}{|c|}{$\begin{array}{l}\text { Became food } \\
\text { insecure for the } \\
\text { second time in } \\
\text { 5th grade }\end{array}$} \\
\hline & & $\beta$ & $P$ & $\beta$ & $P$ & $\beta$ & $P$ & $\beta$ & $P$ & $\beta$ & $P$ & $\beta$ & $P$ & $\beta$ & $P$ \\
\hline \multicolumn{16}{|c|}{ Social skill composite score } \\
\hline All & 4710 & -0.077 & 0.036 & -0.132 & 0.008 & 0.011 & 0.786 & -0.099 & 0.278 & 0.089 & 0.179 & 0.025 & 0.776 & 0.111 & 0.195 \\
\hline Boys & 2310 & -0.037 & 0.389 & -0.172 & 0.012 & -0.020 & 0.714 & 0.022 & 0.854 & 0.066 & 0.415 & 0.075 & 0.437 & 0.123 & 0.355 \\
\hline Girls & 2400 & -0.119 & 0.016 & -0.104 & 0.078 & 0.039 & 0.497 & -0.161 & 0.193 & 0.135 & 0.139 & 0.002 & 0.986 & 0.078 & 0.276 \\
\hline \multicolumn{16}{|c|}{ Interpersonal relationship score } \\
\hline All & 4710 & -0.074 & 0.139 & -0.118 & 0.059 & 0.016 & 0.794 & -0.083 & 0.500 & 0.065 & 0.435 & 0.052 & 0.618 & 0.222 & 0.089 \\
\hline Boys & 2310 & -0.016 & 0.793 & -0.167 & 0.066 & -0.035 & 0.692 & 0.113 & 0.444 & 0.070 & 0.495 & 0.080 & 0.540 & 0.227 & 0.249 \\
\hline Girls & 2400 & -0.133 & 0.061 & -0.083 & 0.268 & 0.058 & 0.466 & -0.207 & 0.241 & 0.063 & 0.580 & 0.047 & 0.732 & 0.204 & 0.144 \\
\hline \multicolumn{16}{|c|}{ Self-control score } \\
\hline All & 4710 & -0.057 & 0.225 & -0.124 & 0.041 & 0.021 & 0.715 & -0.093 & 0.409 & 0.030 & 0.736 & 0.073 & 0.438 & 0.103 & 0.230 \\
\hline Boys & 2310 & -0.015 & 0.793 & -0.194 & 0.011 & 0.045 & 0.540 & 0.055 & 0.728 & -0.022 & 0.841 & 0.193 & 0.080 & 0.107 & 0.389 \\
\hline Girls & 2400 & -0.124 & 0.050 & -0.078 & 0.282 & 0.013 & 0.874 & -0.195 & 0.168 & 0.119 & 0.312 & -0.015 & 0.898 & 0.095 & 0.285 \\
\hline \multicolumn{16}{|c|}{ Approaches to learning score } \\
\hline All & 4710 & -0.118 & 0.015 & -0.182 & 0.011 & 0.028 & 0.668 & -0.073 & 0.485 & 0.131 & 0.111 & 0.033 & 0.699 & 0.145 & 0.099 \\
\hline Boys & 2310 & -0.034 & 0.575 & -0.148 & 0.017 & -0.101 & 0.250 & 0.129 & 0.430 & 0.084 & 0.435 & 0.017 & 0.893 & 0.223 & 0.063 \\
\hline Girls & 2400 & -0.190 & 0.003 & -0.200 & 0.056 & 0.151 & 0.051 & -0.195 & 0.138 & 0.173 & 0.116 & 0.085 & 0.439 & 0.060 & 0.541 \\
\hline \multicolumn{16}{|c|}{ Externalising behaviour score } \\
\hline All & 4710 & 0.059 & $0 \cdot 127$ & 0.103 & 0.064 & 0.019 & 0.654 & 0.148 & 0.062 & -0.132 & 0.062 & 0.060 & 0.516 & 0.028 & 0.763 \\
\hline Boys & 2310 & 0.085 & 0.112 & 0.180 & 0.070 & -0.009 & 0.900 & 0.209 & 0.063 & -0.130 & 0.241 & -0.008 & 0.929 & 0.066 & 0.651 \\
\hline Girls & 2400 & 0.030 & 0.467 & 0.055 & 0.200 & 0.067 & 0.167 & 0.046 & 0.656 & -0.184 & 0.022 & 0.110 & 0.304 & 0.046 & 0.586 \\
\hline
\end{tabular}

"Food insecurity is defined as $\geq 1$ affirmative response on the United States Department of Agriculture's Household Food Security Survey Module.

$\dagger P$ values are adjusted for within-child correlation among repeated observations, and the use of longitudinal Early Childhood Longitudinal Study-Kindergarten sampling weights adjusted for oversampling and non-response across the three survey rounds.

‡Controlling for child’s overall activity level, In(height), In(weight), television watching, non-parental child care hours and arrangements, type of school, number of siblings, household size, a series of household income category a series of parental education-level indicator variables, a general linear time trend, a linear time trend for children attending a public-type school, time-varying county-level characteristics, and a series of county-level indicator variables and linear time trends. 
In addition to contemporaneous relationships, we find that children have below-average social skill scores following an early transition from food insecurity in the 1st grade to food security in the 3 rd grade. A negative transitional effect of food insecurity experiences on children's social skills is consistent with persistent psychological stress associated with the timing of intermittent food insecurity experiences; and estimates based on sex-stratified samples indicate that the association is strongest among boys. Previous analyses indicate that past financial hardship reduces the extent to which boys aged 14-17 years feel in control of events in their life ${ }^{(34)}$, and teachers report more learning and social adjustment problems for boys aged 10-14 years who experienced stressful life events within the past year ${ }^{(37)}$. Although 3 rdgrade boys in our analytic sample are relatively younger at the age of 8-11 years, the negative transitional effect we find is probably due to persistent stress associated with household financial hardship occurring in the 1st grade. After adjusting for increases in the price level, a one-tailed mean comparison test indicates significantly $(P<0.046)$ higher household incomes during the 3 rd grade relative to the 1 st grade for boys experiencing this particular transition. While a number of factors are related to household income, parental education levels also significantly $(P<0.041)$ increased over the same period of time.

Furthermore, Jyoti et al. ${ }^{(21)}$ analysed children's development from kindergarten to 3rd grade and found that boys who transition to food security in the 3 rd grade have composite social skill scores that change by $-0.080(P<0.038)$. We find that this negative effect on boys' social skills persists through the 5 th grade and is larger in size at $-0 \cdot 172(P<0 \cdot 012)$. In contrast, they find that girls benefit from the same transition with a change in composite social skill scores of $0 \cdot 123$ $(P<0.001)$. While our estimate of $-0.104(P<0.078)$ indicates no significant effect of this particular transition through the 5 th grade, we do find corroborating evidence that girls benefit from not experiencing food insecurity; girls with no food insecurity experiences during elementary school have composite social skill scores that are $0 \cdot 119(P<0 \cdot 016)$ higher, on average. The difference in our conclusions for the persistency of the benefits from the early transition for girls is most likely due to the extended time horizon of our analysis, and the use of subject-specific models that allow for both contemporaneous and transitional relationships.

Finally, determining that children's self-control, attentiveness and task persistence are differentially affected by food insecurity, relative to interpersonal skills or the propensity to engage in aggressive or disruptive classroom behaviour, has important implications because hindered social skill development can undermine the effectiveness of classroom-based learning ${ }^{(38)}$ and persist into adulthood ${ }^{(39,40)}$. Moreover, the social skill outcomes negatively affected by food insecurity experiences are those most likely to be influenced by metabolic stress in controlled experiments ${ }^{(27,28)}$. Public policy responses to ameliorate household food insecurity in developed countries include a wide range of programmes designed to increase access to available food ${ }^{(41)}$. However, the effectiveness of existing programmes in eradicating food insecurity experiences is questionable. Recent analyses have found that food insecurity remains strongly related to low consumption of healthy foods, even for those currently receiving food $\operatorname{aid}^{(42)}$, and that below-average nutrition education among households participating in food aid programmes results in unhealthy dietary choices ${ }^{(43)}$. Providing comprehensive assistance that includes both food aid and nutrition education to families reporting food insecurity can help prevent unfavourable nutritional and non-nutritional consequences for young children.

\section{Acknowledgements}

The present study received no specific grant from any funding agency in the public, commercial or not-for-profit sectors. L. L. H. performed the analyses and wrote the manuscript. There are no conflicts of interest to declare. The author would like to thank Alok Bhargava for many helpful discussions and two reviewers for several helpful comments.

\section{References}

1. Nord M, Andrews M \& Carlson S (2009) Household Food Security in the United States, 2008. Economic Research Report no. 83. Washington, DC: Economic Research Service, United States Department of Agriculture.

2. Campbell CC (1991) Food insecurity: a nutritional outcome or a predictor variable? J Nutr 121, 408-415.

3. Darmon N, Ferguson EL \& Briend A (2002) A cost constraint alone has adverse effects on food selection and nutrient density: an analysis of human diets by linear programming. J Nutr 132, 3764-3771.

4. Darmon N, Ferguson E \& Briend A (2003) Do economic constraints encourage the selection of energy dense diets? Appetite 41, 315-322.

5. Drewnowski A \& Darmon N (2005) Food choices and diet costs: an economic analysis. J Nutr 135, 900-904.

6. Drewnowski A \& Darmon N (2005) The economics of obesity: dietary energy density and energy cost. Am J Clin Nutr 82, 265S-273S.

7. Andrieu E, Darmon N \& Drewnowski A (2006) Low-cost diets: more energy, fewer nutrients. Eur J Clin Nutr 60 , 434-436.

8. Maillot M, Darmon N, Darmon M, et al. (2007) Nutrientdense food groups have high energy costs: an econometric approach to nutrient profiling. J Nutr 137, 1815-1820.

9. Dietz WH (1995) Does hunger cause obesity? Pediatrics $\mathbf{9 5}$, 766-767.

10. Bhargava A, Jolliffe D \& Howard LL (2008) Socio-economic, behavioural and environmental factors predicted body weights and household food insecurity scores in the Early Childhood Longitudinal Study-Kindergarten. Br J Nutr 100, 438-444.

11. Kleinman RE, Murphy JM, Little M, et al. (1998) Hunger in children in the United States: potential behavioral and emotional correlates. Pediatrics 101, E3.

12. Weinreb L, Wehler C, Perloff J, et al. (2002) Hunger: its impact on children's health and mental health. Pediatrics 110, e41.

13. Murphy JM, Wehler CA, Pagano ME, et al. (1998) Relationship between hunger and psychosocial functioning in low-income american children. J Am Acad Child Adolesc Psychiatry 37, 163-170. 
14. Alaimo K, Olson CM, Edward A, et al. (2001) Food insufficiency and America's school-aged children's cognitive, academic, and psychosocial development. Pediatrics 108, $44-53$.

15. Alaimo K, Olson CM, Edward A, et al. (2001) Food insufficiency, family income, and health in US preschool and school-aged children. Am J Public Health 91, 781-786.

16. Alaimo K, Olson CM \& Frongillo EA (2002) Family food insufficiency, but not low family income, is positively associated with dysthymia and suicide symptoms in adolescents. J Nutr 132, 719-725.

17. Dunifon R \& Kowaleski-Jones L (2003) The influences of participation in the national school lunch program and food insecurity on child well-being. Soc Serv Rev 77, 72-92.

18. Winicki J \& Jemison K (2003) Food insecurity and hunger in the kindergarten classroom: its effect on learning and growth. Contemp Econ Policy 21, 145-157.

19. Cook JT, Frank DA, Berkowitz C, et al. (2004) Food insecurity is associated with adverse health outcomes among human infants and toddlers. J Nutr 134, 1432-1438.

20. Ashiabi G (2005) Household food insecurity and children's school engagement. J Child Poverty 11, 3-17.

21. Jyoti DF, Frongillo EA \& Jones SJ (2005) Food insecurity affects school children's academic performance, weight gain, and social skills. J Nutr 135, 2831-2839.

22. Kirkpatrick SI \& Tarasuk V (2008) Food insecurity is associated with nutrient inadequacies among canadian adults and adolescents. J Nutr 138, 604-612.

23. Cronbach LJ (1951) Coefficient alpha and the internal structure of tests. Psychometrika 16, 297-334.

24. Office of Nutrition Policy and Promotion (2007) IncomeRelated Household Food Security in Canada. Report no. H164-42/2007E. Ottawa: Health Canada.

25. Bickel G, Nord M, Price M, et al. (2000) Guide to Measuring Household Food Security in the U.S.: Revised 2000. Alexandria, VA: USDA, Food and Nutrition Service.

26. Radimer KL (2002) Measurement of household food security in the USA and other industrialised countries. Public Health Nutr 5, 859-864.

27. Pollitt E, Cueto S \& Jacoby ER (1998) Fasting and cognition in well- and undernourished schoolchildren: a review of three experimental studies. Am J Clin Nutr 67 , $779 \mathrm{~S}-784 \mathrm{~S}$

28. Wyon DP, Abrahamsson L, Jartelius M, et al. (1997) An experimental study of the effects of energy intake at breakfast on the test performance of 10-year-old children in school. Int J Food Sci Nutr 48, 5-12.

29. Bolger KE, Patterson CJ, Thompson WW, et al. (1995) Psychosocial adjustment among children experiencing persistent and intermittent family economic hardship. Child Dev 66, 1107-1129.
30. Ackerman BP, Brown ED \& Izard CE (2004) The relations between persistent poverty and contextual risk and children's behavior in elementary school. Dev Psychol 40, 367-377.

31. Tourangeau K, Nord C, Lê T, et al. (2006) Early Childhood Longitudinal Study, Kindergarten Class of 1998-99 (ECLS-K), Combined User's Manual for the ECLS-K Fifth-Grade Data Files and Electronic Codebooks (NCES 2006-032). Washington, DC: National Center for Education Statistics, U.S. Department of Education.

32. Gresham FM \& Elliott SN (1990) Social Skills Rating Scale: Elementary Scale A ("How Often?"). Circle Pines, MN: American Guidance Service, Inc.

33. Zeger SL, Liang K-Y \& Albert PS (1988) Models for longitudinal data: a generalized estimating equation approach. Biometrics 44, 1049-1060.

34. Conger RD, Conger KJ, Matthews LS, et al. (1999) Pathways of economic influence on adolescent adjustment. Am J Community Psychol 27, 519-541.

35. Rudolph KD \& Hammen C (1999) Age and gender as determinants of stress exposure, generation, and reactions in youngsters: a transactional perspective. Child Dev 70, 660-677.

36. Conger RD, Conger KJ, Elder JGH, et al. (1993) Family economic stress and adjustment of early adolescent girls. Dev Psychol 29, 206-219.

37. Goodman SH, Brumley HE, Schwartz KR, et al. (1993) Gender and age in the relation between stress and children's school adjustment. I Early Adolescence 13, 329-345.

38. Alexander KL, Entwisle DR \& Dauber SL (1993) First-grade classroom behavior: its short- and long-term consequences for school performance. Child Dev 64, 801-814.

39. Dodge KA \& Pettit GS (2003) A biopsychosocial model of the development of chronic conduct problems in adolescence. Dev Psychol 39, 349-371.

40. Masten AS, Roisman GI, Long JD, et al. (2005) Developmental cascades: linking academic achievement and externalizing and internalizing symptoms over 20 years. Dev Psychol 41, 733-746.

41. Barrett CB (2002) Chapter 40. Food security and food assistance programs. In Handbook of Agricultural Economics, pp. 2103-2190 [LG Bruce and CR Gordon, editors]. Amsterdam: Elsevier.

42. Mejean C, Deschamps V, Bellin-Lestienne C, et al. (2010) Associations of socioeconomic factors with inadequate dietary intake in food aid users in France (The ABENA study 2004-2005). Eur J Clin Nutr 64, 374-382.

43. Bhargava A (2004) Socio-economic and behavioural factors are predictors of food use in the National Food Stamp Program Survey. Br J Nutr 92, 497-506. 